\title{
KAJIAN KUAT GESER LANGSUNG BETON MEMADAT SENDIRI DENGAN KADAR FLY ASH 50\% DAN 60\%
}

\author{
${ }^{1)}$ Favian Gustav Mulya, ${ }^{2}$ Agus Setiya Budi, ${ }^{3)}$ Senot Sangadji \\ 1) Mahasiswa Program Studi Teknik Sipil Fakultas Teknik Universitas Sebelas Maret \\ 2),3) Pengajar Program Studi Teknik Sipil Fakultas Teknik Universitas Sebelas Maret \\ Jl. Ir. Sutami 36 A, Kentingan Surakarta 57126 \\ Email : favgustav@student.uns.ac.id
}

\begin{abstract}
Concrete is the most widely used construction material in various developments. But the production of one ton of cement produces $\mathrm{CO}_{2}$ equivalent to 0.55 tons and requires carbon fuel which will produce $\mathrm{CO}_{2}$ emissions of 0.45 tons needed by Global Warming (Davidovits, 1994). The use of Fly ash as a cement subtituent is being widely approved and is starting to be widely applied. Fly ash itself is industrial waste produced from coal combustion. Fly Ash has very fine particles with diameters between 1 - 150 um and round granules (Siddique, 2004). Containing high silica (SiO2), fly ash can be used as a substitute for cement which is a binder in making concrete. Fly ash with $>50 \%$ and the use of superplastictizers can produce ductile concrete structures which can flow and compact themselves, known as High Volume Fly Ash - Self Compacting Concrete. This research will examine the shear capacity of High Volume Fly Ash - Self Compacting Concrete (HVFA - SCC) with 50\% dan 60\% fly ash content, then will be compared with normal concrete. The specimen used in this research is double L reinforced concrete with cross-sectional area of $10 \mathrm{~cm} \times 20 \mathrm{~cm} \times 36 \mathrm{~cm}$. Shear strenght test using a LVDT. From this test, we will get the Load-Displacement relationship chart, and maximum shear stress of HVFA-SCC 50\%, 60\% and normal concrete. From the results of the study it was found that the double L HVFA-SCC had shear strength greater than normal concrete.
\end{abstract}

Keywords: Fly ash, HVFA-SCC, Shear strenght.

\begin{abstract}
Abstrak
Beton adalah bahan konstruksi yang banyak dipakai dalam pembangunan infrastruktur. Akan tetapi, proses produksi semen menimbulkan adanya $\mathrm{CO}_{2}$ yang cukup besar yaitu pada satu ton semen menghasilkan 0,55 ton $\mathrm{CO}_{2}$ serta membutuhkan bahan bakar karbon yang dapatmengeluarkan emisi $\mathrm{CO}_{2}$ setara 0,45 ton serta menyebabkan Global Warming. Fly Ash merupakan material substitusi semen yang saat ini sedang banyak diteliti serta digunakan. Fly ash merupakan limbah industri berasal dari pembakaran batubara, dengan ukuran diameter 1-150 $\mu \mathrm{m}$ (Siddique, 2004). Fly Ash memiliki kandungan $\mathrm{SiO}_{2}$ yang relatif tinggi, sehingga bisa digunakan sebagai material pozzolan substitusi semen yang bersifat mengikat dalam pembuatan beton. Fly Ash dengan kandungan $>50 \%$ disertai dengan tambahan material superplastictizer akan dapat menjadikan struktur beton yang bersifat daktail dapat menggalir serta memadat mandiri, campuran ini disebut sebagai High Volume Fly Ash-Self Compacting Concrete (HVFA - SCC). Dalam penelitian ini akan dibahas kuat geser langsung beton HVFA - SCC pada kandungan fly ash 50\% dan 60\% kemudian hasil tersebut akan dikomparasikan dengan balok beton normal. Dalam penelitian ini digunakan balok dobel L bertulang dengan penampang 10x 20x36 cm terdiri atas 5 balok beton normal dan 5 balok HVFA-SCC dengan kandungan fly ash 50\% serta 5 balok HVFA-SCC dengan kandungan fly ash 60\%. Pada uji kuat geser langsung digunakkan alat yaitu LVDT, dari pengujian ini akan diperoleh grafik hubungan Load-Displacement dengan tegangan geser maksimum beton HVFA-SCC 50\%, 60\% serta balok beton normal. Berdasarkan hasil penelitian benda uji dobel L HVFA-SCC memiliki kuat geser maksimum lebih besar daripada beton normal.
\end{abstract}

Kata Kunci : Fly ash, HVFA-SCC, Kuat geser

\section{PENDAHULUAN}

Berkembangnya dunia konstruksi khususnya pada bidang teknologi beton, merupakan akibat dari kebutuhan di lapangan serta adanya penelitian. Salahsatu bentuk perkembangan diantaranya adalah penggabungan prinsip beton High Volume Fly Ash Concrete (HFVA) dengan Self Compacting Concrete (SCC). Hal tersebut menyebabkan adanya inovasi dari dua jenis teknologi beton tersebut yang kemudian disebut sebagai HFVA-SCC. Untuk mendapatkan kuat tekan yang tinggi, digunakan variasi water content yang dikombinasikan dengan superplasticizer, kadar fly ash, dan agregat pada mix design beton.

Berdasarkan hal tersebut HFVA-SCC akan sangat bermanfaat dalam dunia konstruksi dan sangat luas penerapannya pada struktur bangunan seperti konstruksi yang memerlukan beton yang dapat masuk ke sela - sela tulangan yang rapat serta efisien biaya dan ramah lingkungan, untuk itu akan dilakukan penelitian yang yang mengkaji peilaku kuat geser murni High Volume Fly Ash Self-Compacting Concrete (HVFA-SCC) dengan kandungan fly ash 60\% dan 50\% kemudian dibandingkan dengan beton normal. Umur beton yang diuji adalah 28 hari. 


\section{METODE}

Vol 8, No 3 (2020): September

Penelitian ini bersifat eksperimental dan dilakukan di Laboratorium Material Teknik Sipil Universitas Sebelas Maret. Studi ini menggunakan benda uji berupa balok dobel L ukuran 200x100x360 mm tanpa menggunakan fly ash (Beton Normal), 50\% serta 60\%. Masing-masing dibuat tiga benda uji. Uji yang dilaksanakan yaitu uji kuat tekan pada alat UTM (Universal Testing Machine) kemudian dilakukan pengolahan data. Model benda uji ditampilkan pada Gambar 1 berikut
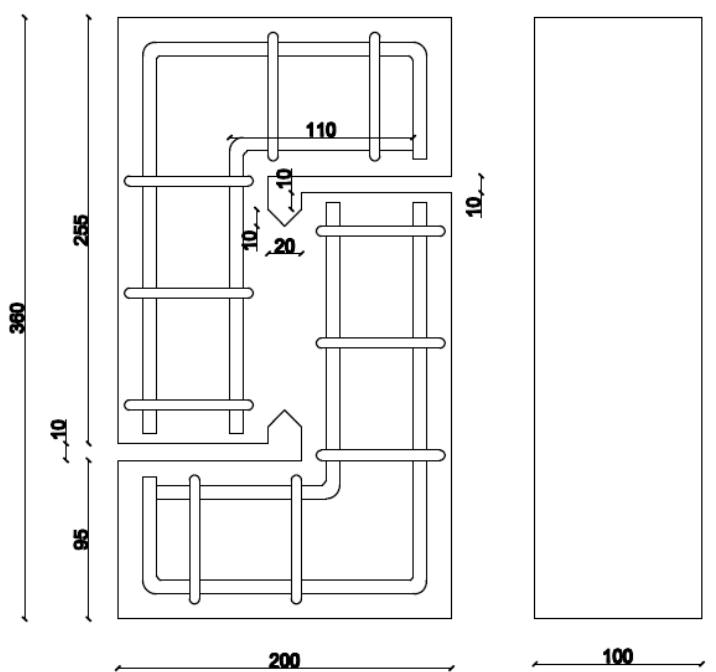

Gambar 1. Model benda uji dobel L

Setting up alat pengujian disajikan pada Gambar 2

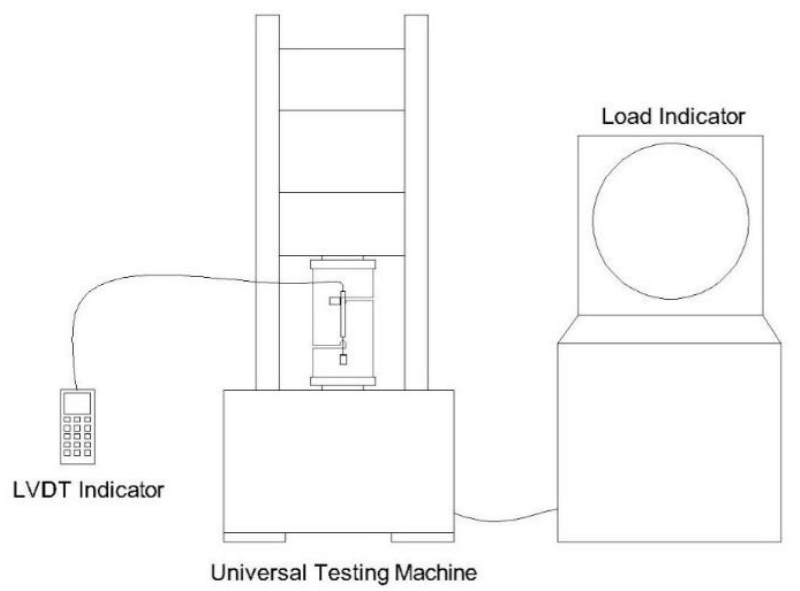

Gambar 2. Setting up alat pengujian benda uji dobel L

\section{Tegangan Beton}

Persamaan tegangan dinyatakan sebagai berikut $\tau=\frac{F}{A}$

dengan :

$\tau \quad=$ tegangan geser $(\mathrm{MPa})$

$\mathrm{F} \quad=$ gaya tekan maksimum $(\mathrm{N})$

A $=$ luas bidang geser sampel uji dobel $\mathrm{L}\left(\mathrm{mm}^{2}\right)$ 


\section{HASIL DAN PEMBAHASAN}

\section{Hasil Uji Material}

Uji material agregat halus yaituujikandungan zat organik, kadar lumpur, berat jenis. Adapun hasil uji dapat dilihat pada Tabel 1.

Tabel 1. Hasil uji agregat halus

\begin{tabular}{lccc}
\hline \multicolumn{1}{c}{ Jenis Pengujian } & Hasil Pengujian & Standar & Keterangan \\
\hline Kandungan Lumpur & $0,5 \%$ & Maksimal $5 \%$ & Memenuhi syarat \\
Berat Jenis Kering Permukaan Jenuh & $2,475 \mathrm{gr} / \mathrm{cm} 3$ & $2,5-2,7 \mathrm{gr} / \mathrm{cm} 3$ & Memenuhi syarat \\
Kandungan Zat Organik & Kuning Muda & Kuning Muda & Memenuhi syarat \\
Berat Jenis Semu & $2,594 \mathrm{gr} / \mathrm{cm}^{3}$ & - & - \\
Berat Jenis Kering & $2,401 \mathrm{gr} / \mathrm{cm}^{3}$ & - & - \\
Absorpsi & $3,093 \%$ & - & - \\
\hline
\end{tabular}

Agregat kasar yang diuji meliputi keausan agregat dan specific gravity, hasil uji agregat kasar ditampilkan pada Tabel 2.

Table 2. Hasil uji agregat kasar

\begin{tabular}{lccc}
\hline \multicolumn{1}{c}{ Jenis Pengujian } & Hasil Pengujian & Standar & Kesimpulan \\
\hline Keausan Agregat & $26,92 \%$ & $<50 \%$ & Memenuhi syarat \\
Berat Jenis Kering Permukaan Jenuh & $2,718 \mathrm{gr} / \mathrm{cm}^{3}$ & $2,5-2,7 \mathrm{gr} / \mathrm{cm}^{3}$ & Memenuhi syarat \\
Berat Jenis Semu & $2,752 \mathrm{gr} / \mathrm{cm}^{3}$ & - & - \\
Berat Jenis Kering & $2,698 \mathrm{gr} / \mathrm{cm}^{3}$ & - & - \\
Absorbtion & $0,733 \%$ & - & - \\
\hline
\end{tabular}

\section{Hasil Uji Beton Segar}

Pengujian beton segar dilakukan pada beton HVFA-SCC $60 \%$ dengan uji yang dilakukan diantaranya $V$-funnel, $L$ Box dan Flow Table Test sementara pengujian beton normal dilakukan uji slump. Hasil uji beton segar dinyatakan dalam Tabel 4 hingga Tabel 6.

Tabel 4. Hasil uji flow table test HVFA-SCC 60\%

\begin{tabular}{|c|c|c|c|c|c|c|c|}
\hline \multirow{3}{*}{ Kode } & \multicolumn{4}{|c|}{ Flow Table Test } & \multirow{2}{*}{\multicolumn{3}{|c|}{$\begin{array}{l}\text { Syarat menurut } \\
\text { EFNARC }\end{array}$}} \\
\hline & & Diame & & Waktu & & & \\
\hline & $\begin{array}{c}\text { d1 } \\
(\mathrm{mm})\end{array}$ & $\begin{array}{c}\mathrm{d} 2 \\
(\mathrm{~mm})\end{array}$ & $\begin{array}{c}d_{\text {rata-rata }} \\
(\mathrm{mm})\end{array}$ & $\begin{array}{c}t_{50} \\
(d t)\end{array}$ & $\begin{array}{l}\mathrm{T}_{50} \\
(\mathrm{~s})\end{array}$ & $\begin{array}{c}d_{\text {rata-rata }} \\
(\mathrm{mm})\end{array}$ & Keterangan \\
\hline HVFA $50 \%$ & 650 & 620 & 635 & 3 & $2-5$ & $550-850$ & Memenuhi \\
\hline HVFA $60 \%$ & 580 & 600 & 590 & 4 & $2-5$ & $550-850$ & Memenuhi \\
\hline
\end{tabular}

Tabel 5. Hasil pengujian l-box HVFA-SCC 60\%

\section{L-Box Type}

\begin{tabular}{cccccc} 
Kode & $\begin{array}{c}\mathbf{h}_{\mathbf{1}} \\
(\mathbf{m m})\end{array}$ & $\begin{array}{c}\mathbf{h}_{\mathbf{2}} \\
\mathbf{( \mathbf { m m } )}\end{array}$ & $\mathbf{h}_{\mathbf{2}} / \mathbf{h}_{\mathbf{1}}$ & $\begin{array}{c}\text { Syarat } \\
\left(\mathbf{h}_{\mathbf{2}} / \mathbf{h}_{\mathbf{1}}\right)\end{array}$ & Keterangan \\
\hline HVFA $50 \%$ & 90 & 90 & 1 & $0,8-1,0$ & Memenuhi \\
HVFA $60 \%$ & 100 & 90 & 0,9 & $0,8-1,0$ & Memenuhi \\
\hline
\end{tabular}

Tabel 6. Hasil uji v-funnel HVFA-SCC60\%

\begin{tabular}{cccc}
\hline Kode & T(dt) & Syarat(dt) & Keterangan \\
\hline HVFA $50 \%$ & 6 & $6-12$ & Memenuhi \\
HVFA $60 \%$ & 6 & $6-12$ & Memenuhi \\
\hline
\end{tabular}

Hasil uji beton HVFA-SCC60\% dan 50\% seluruhnya sudah memenuhi syarat beton SCC berdasarkan spesifikasi yang ditentukan EFNARC. Sedangkan, nilai slump yang diperoleh pada uji beton normal yaitu $8 \mathrm{~cm}$. Menurut SNI 7656-2012 angka slump yang ditentukan untuk beton normal yaitu 2,5-10 cm. Dengan nilai ini, hasil uji slump memenuhi syarat.

Hasil Uji Benda Uji Geser Murni Beton Dobel L 
Jurnal Matriks Teknik Sipil DOI: https://doi.org/10.20961/mateksi.v8i3

ISSN: 2354-8630

E-ISSN:2723-4223

Tabel 7. Hasil uji kuat geser benda uji

Vol 8, No 3 (2020): September

\begin{tabular}{lccc}
\hline \multirow{2}{*}{ Parameter } & \multicolumn{3}{c}{ Benda Uji } \\
\cline { 2 - 4 } & HVFA.28.50 & HVFA.28.60 & NC.28 \\
\hline Kuat Geser $(\mathrm{MPa})$ & 3,11 & 3,52 & 2,79 \\
\hline
\end{tabular}

Pada pengujian balok dobel L HVFA-SCC 50\%, 60\% dan beton normal , pembacaan displacement menggunakan LVDT Indicator yang terhubung langsung dengan LVDT. Hubungan beban dan displacement ratarata hasil pengujian benda uji HVFA-SCC 60\%, 50\% dan normal disajikan pada gambar 4, 5 dan

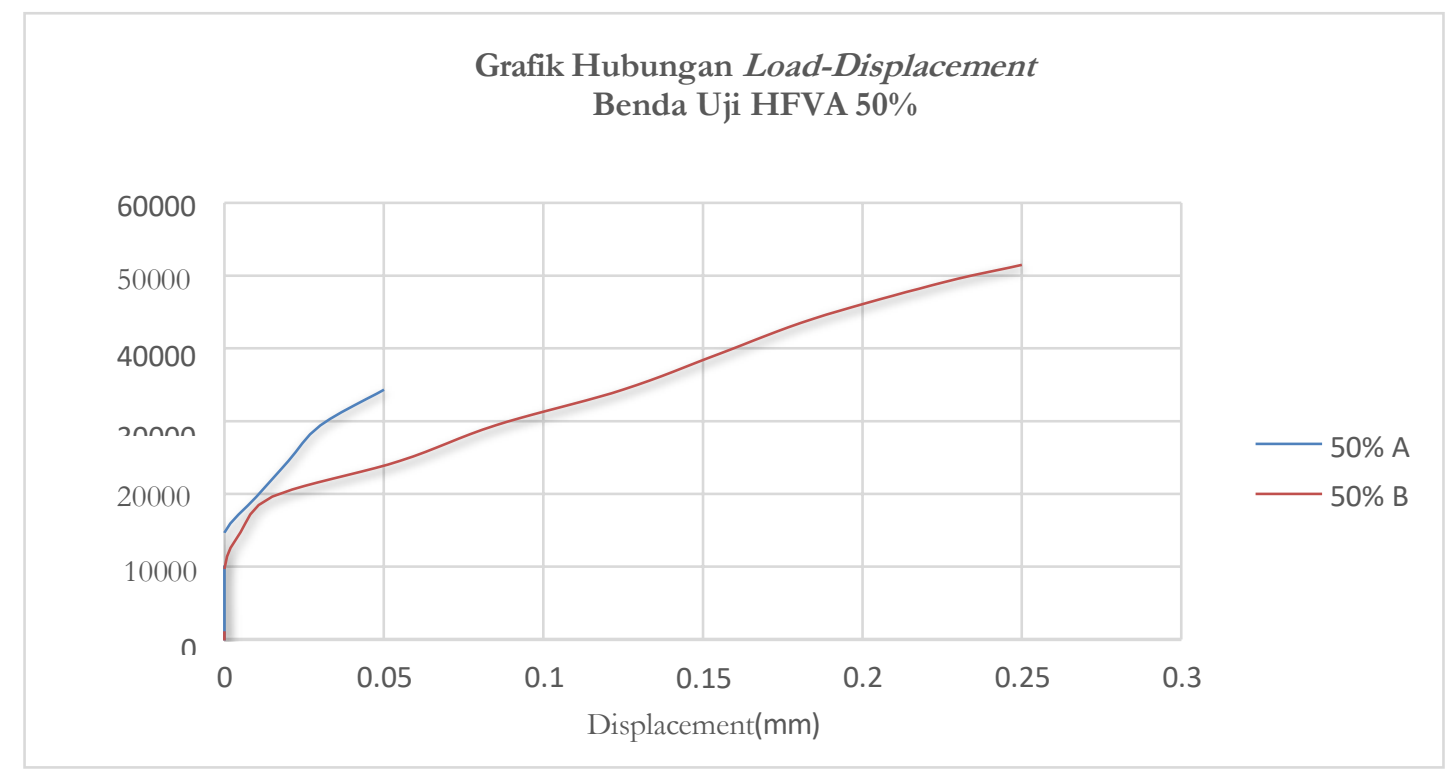

Gambar 4. Hubungan load-displacement beton dobel L HVFA-SCC 50\%

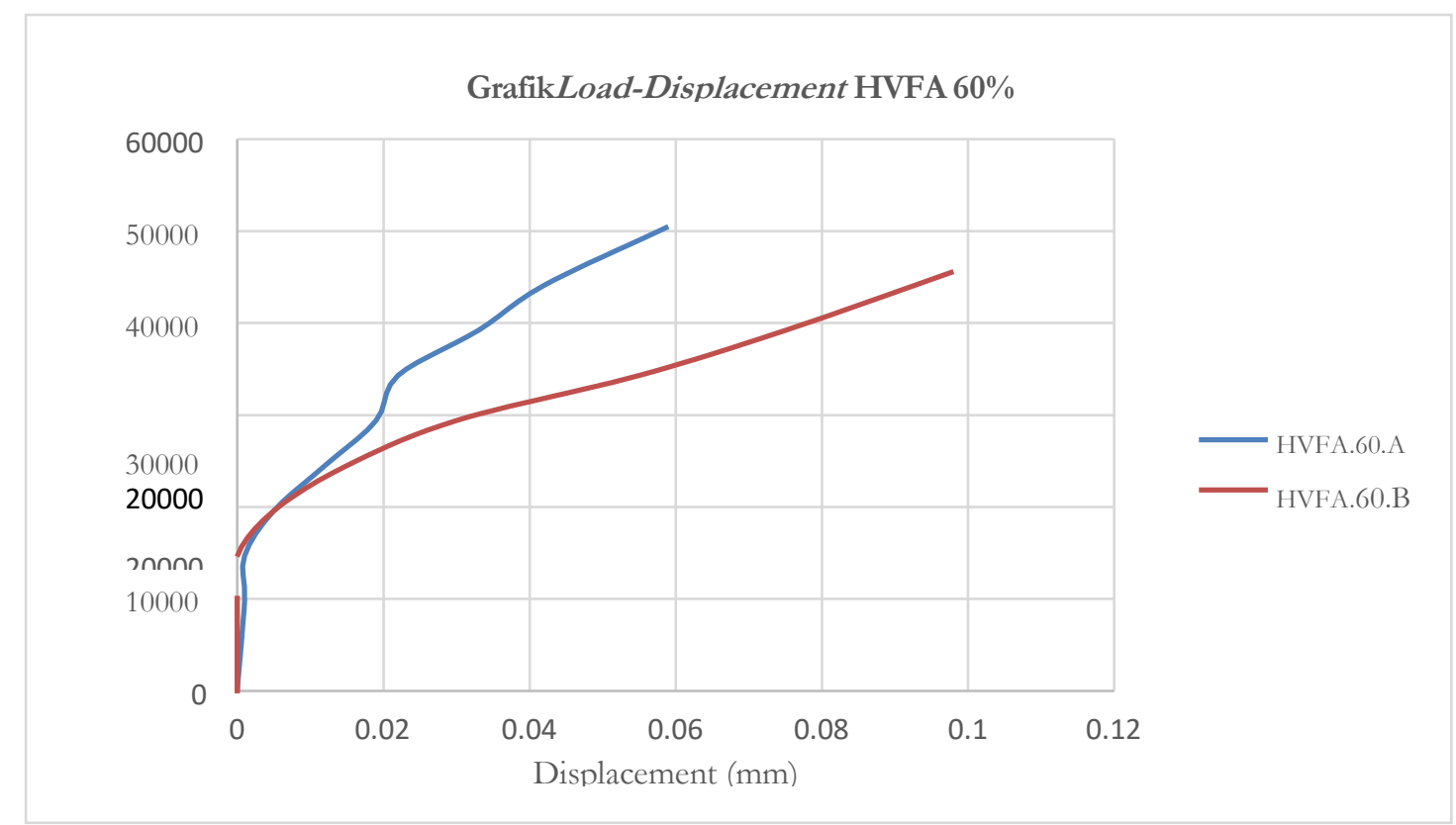

Gambar 5. Hubungan load-displacement beton dobel L HVFA-SCC 60\% 


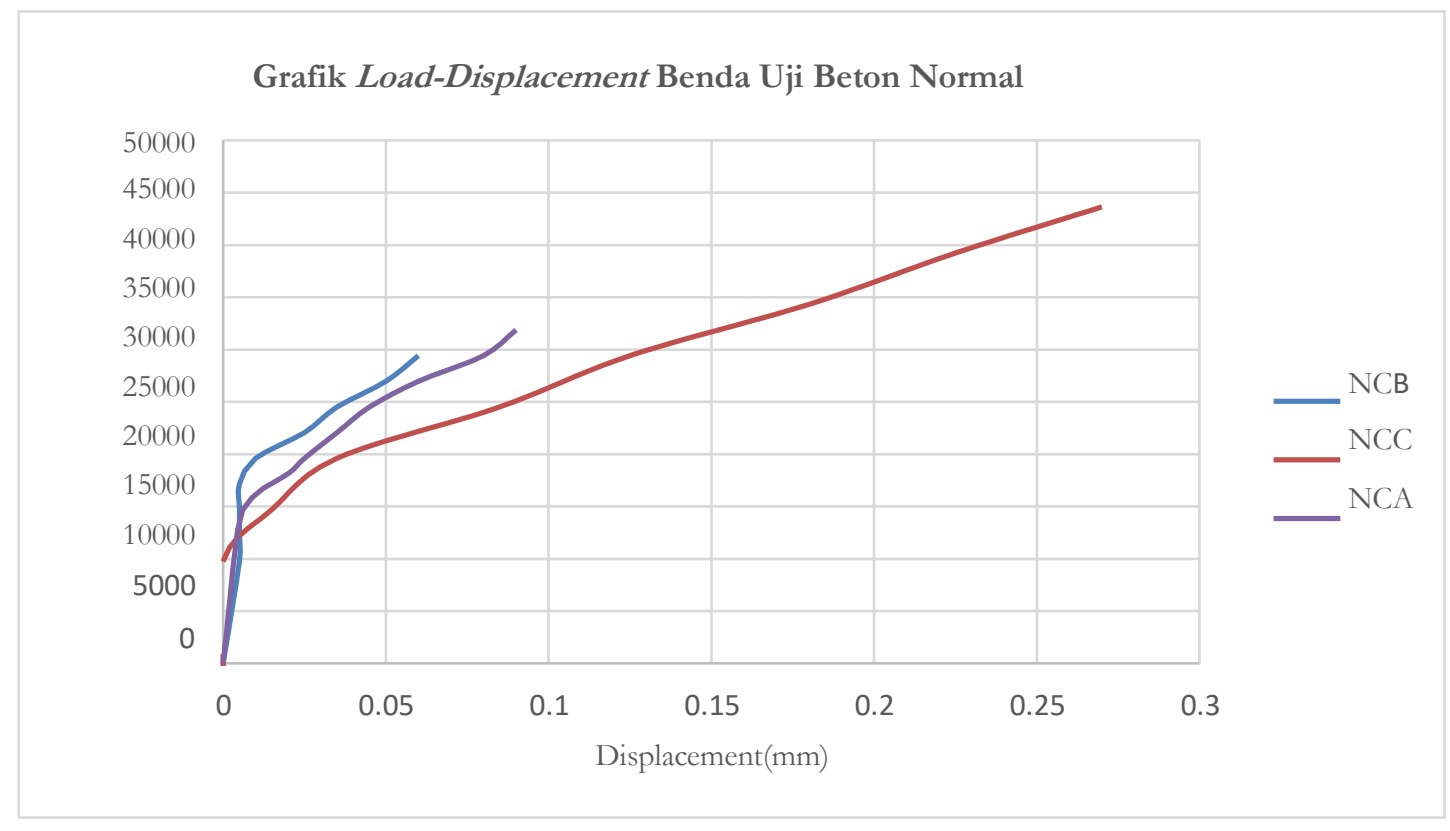

Gambar 6. Hubungan load-displacement beton dobel L normal

Dari data yang sudah diadapatkan diatas, dapat kita identifikasi bahwa beban maksimum yang dapat diterima beton HVFA-SCC 50\% yaitu $42906 \mathrm{~N}$ lebih besar 22\% daripada beton normal, beton HVFA-SCC 60\% dapat menerima beban maksimum paling tinggi yaitu $48054 \mathrm{~N}$ lebih besar $37 \%$ daripada beton normal yang hanya dapat menerima beban maksimum sebesar 34978 N. Berdasarkan data diatas karena kadar 60\% memiliki kepadatan yang tinggi, sehingga dapat menahan beban maksimum yang paling tinggi dibandingkan dengan kadar $50 \%$ dan normal

\section{KESIMPULAN}

Dari hasil analisis serta pengujian yang dilakukan secara eksperimen terkait kajian kuat geser langsung beton HVFA-SCC dengan kandungan fly ash 60\% dan 50\% untuk benda uji balok dobel L, dapat diambil kesimpulan sebagai berikut:

1. Berdasarkan hasil pengujian menggunakan alat UTM, beton HVFA-SCC dapat menahan beban gaya geser yang lebih besar daripada beton normal pada umur 28 hari. Artinya, penambahan kadar fly ash dengan presentase $50 \%$ dan $60 \%$ dapat menahan beban gaya geser lebih besar dibanding beton normal.

2. Beton HVFA-SCC mempunyai nilai kuat geser yang lebih besar dibandingkan beton normal. Beton dengan tambahan fly ash dengan kandungan 60\% memperoleh nilai kuat geser yang paling tinggi, yaitu sebesar 3,52 $\mathrm{MPa}$. Sementara beton dengan kandungan $f y$ ash sebesar 50\% memperoleh kuat geser sebesar 3,11 $\mathrm{MPa}$, serta pada beton normal mendapat nilai kuat geser sebesar 2,79 MPa.

\section{UCAPAN TERIMAKASIH}

Penulis menyampaikan ucapan terima kasih kepada kepada Bapak Agus Setiya Budi, S.T., M.T. dan Bapak Dr. Senot Sangadji S.T., M.T., sebagai pembimbing yang telah membagi ilmu serta waktu hingga penelitian ini terselesaikan. Terima kasih penulis sampaikan kepada tim beton tjap orangtua selaku tim yang telah bekerja keras dalam penelitian ini.

\section{REFERENSI}

America Concrete Institute, 2011, “ACI 318-11: Building Code Requirements For Structural Concrete And Commentary", American Concrete Institute, Farmington Hills, MI.

Badan Standarisasi Nasional, 2000, "SNI 03-2834-2000 : Tata Cara Pembuatan Rencana Campuran Beton Normal”. Badan Standarisasi Nasional, Jakarta. 
Badan Standarisasi Nasional, 2019, "SNI 03-2847-2019 : Persyaratan Beton Struktural Untuk Bangunan Gedung Dan Penjelasan Sebagai Revisi Dari Standar Nasional Indonesia 2847 : 2013”, Badan Standarisasi Nasional, Jakarta.

EFNARC, 2005, " The European Guidelines for Self-Compacting Concrete", The European Guidelines for Self Compacting Concrete. 